\title{
Dynamics of impact of sphere on flat surfaces of polymer matrix composites
}

\author{
MANISH ROY \\ Defence Metallurgical Research Laboratory, P.O. Kanchanbagh, Hyderabad 500 058, India \\ MS received 26 February 1999; revised 14 July 1999
}

\begin{abstract}
The primary objective of this work was to evaluate the influence of various reinforcements and matrix materials on the dynamic hardness of polymer matrix materials (PMC). Therefore, the impact of a WC ball, using a gravity drop system, was studied on PMCs. The two parameters, coefficient of restitution and dynamic hardness, of PMCs were determined. The mechanical properties of the PMCs were evaluated, and the correlation of the two parameters with the mechanical properties of PMCs was attempted.
\end{abstract}

Keywords. Polymer matrix composites; dynamics of impact.

\section{Introduction}

The dynamics of impact of a hard sphere on a flat surface primarily deals with the coefficient of restitution, and the modes of dissipation of kinetic energy of the sphere to the flat surface. Coefficient of restitution $(e)$ is the ratio of the incident velocity to the rebound velocity, when a target material is impacted with an object. It is an important parameter that indicates the ability of the material to absorb energy. The coefficient of restitution, can be used for determining the dynamic hardness $\left(H_{\mathrm{d}}\right)$ which is the resistance of a material to indentation at very high strain rate (Tirupataiah et al 1990). This property is more relevant than static hardness for characterizing tribological behaviour of the material (Sundararajan 1995). The dynamics of impact of a sphere on a flat metallic surface have been studied extensively (Hertz and Reine 1891; Tabor 1948, 1951; Davis and Hunter 1960; Mock and Duffy 1965; Singer and Evans 1980). The elastic deformation during contact was treated by Hertz (1891), whereas subsequent plastic deformation was analysed by Tabor (1948, 1951), Mock and Duffy (1965) and others (Tabor 1951; Davis and Hunter 1960) who mainly considered the influence of impact velocity on the coefficient of restitution. However, the above-reported studies have not been carried out on polymer and polymer matrix composites. As the polymer matrix composites are considered to be potential material for tribological application, the present investigation has been undertaken to evaluate the influence of nature of matrix and nature of reinforcement on the value of $e$ and in turn, on $H_{\mathrm{d}}$ dynamic hardness of the concerned material. The dependence of these two parameters on mechanical properties will also be examined.

\section{Experimental}

\subsection{Material}

Material used in this investigation can be broadly classified as PMC-I and PMC-II: PMC-I is a composite group of glass fibres, as the reinforcing material, and epoxy, polyester, modified phenolic, and unmodified phenolic resin, as the four different types of matrices; PMC-II is a composite group of epoxy resin, as the matrix, with unidirectional carbon fibre and three varieties of glass fibres viz. 4-weave plain satin, 8-weave plain satin, and plain weave, as the reinforcements. The matrix materials were prepared by dissolving commercially available resin powder in ethyl alcohol. The required size fibres were coated uniformly with the respective matrix resin. The resin-coated plies were then stacked inside a steel mould. While stacking, the orientation of the warp and weft fibre were maintained in all the plies. These plies were subsequently moulded in a hydraulic press at a pressure of $0.3 \mathrm{MPa}$ at room temperature. For phenolic matrix composites, the resin-coated fibres were used to prepare the prepegs in an oven under set temperatures. These prepegs were subsequently stacked and pressed hydraulically $\left(13.5 \mathrm{MPa}\right.$, and $\left.160^{\circ} \mathrm{C}\right)$.

\subsection{Mechanical testing}

The mechanical properties of the PMCs such as the tensile, flexural, and interlaminar shear strengths were determined using a screw-driven Tinius Olsen Universal Testing machine at a cross-head speed of $3 \mathrm{~mm} / \mathrm{min}$. Coefficient of restitution was determined in a gravity drop system as described below. 


\subsection{Determination of coefficient of restitution}

The values of $e$ of the test materials were determined using a gravity drop weight system. The schematic representation of the system is shown in figure 1. The impacting balls were stored in a ball feeder and allowed to drop freely on the target material under the influence of gravity. The test specimen, a flat sample, was fixed rigidly to the target holder at the bottom. The samples were always held normal to the path of the impacting ball.

The description of the system used for velocity measurement has been included with the method of

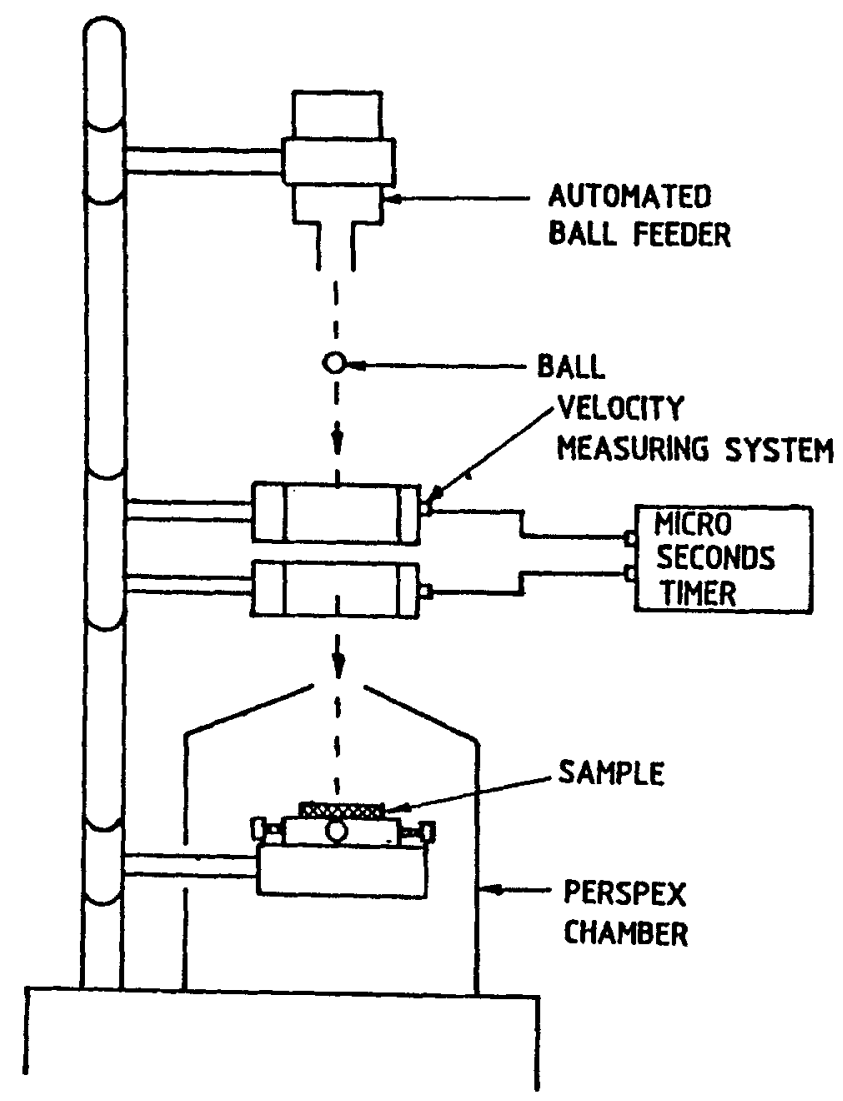

Figure 1. Schematic representation of the system. calculation for incident velocity, for rebound velocity, in the work by Tirupataiah et al (1990).

\section{Results}

\subsection{Mechanical properties}

Table 1 lists the various mechanical properties of the PMC-I, i.e. tensile strength, tensile modulus, flexural strength, flexural modulus, and interlaminar shear strength. These values are average of 3 tests with less than 10\% deviation. From table 1, it is evident that glass phenolic resin (modified) exhibits highest tensile strength, flexural strength, interlaminar shear strength, and flexural modulus. In contrast, the highest tensile modulus is obtained for glass epoxy resin composite. Table 2 lists the various mechanical properties for PMC-II. A comparison between PMC-I and PMC-II indicates that the mechanical properties of the two groups are comparable. However among the PMC-II, epoxy matrix reinforced with unidirectional carbon fibre, has the best mechanical properties. In contrast, epoxy matrix reinforced with $4 \mathrm{H}$ satin weave glass fibre has the best interlaminar shear strength.

\subsection{Coefficient of restitution}

The values of $(e)$ for PMC-I and PMC-II are presented in tables 3 and 4 , respectively. Tables 3 and 4 indicate that $e$ values of PMCs are substantially higher than those recorded for metallic materials by Tirupataiah et al (1990). Metals have values of $e$ ranging from 0.1-0.4. Reinforcement of epoxy matrix by carbon fibre (unidirectional) increases $e$ by $28 \%$ compared to PMC where epoxy resin matrix is reinforced by various glass fibres.

While the composite with epoxy resin as the matrix, in the PMC-I group, shows the highest $e$ value $(0.68)$, the composite with carbon fibres as the reinforcement, in the PMC-II, show the highest $e$ value $(0 \cdot 82)$.

Table 1. Mechanical properties of PMC-I.

\begin{tabular}{lccccc}
\hline Material & $\begin{array}{c}\text { Tensile } \\
\text { strength } \\
(\mathrm{MPa})\end{array}$ & $\begin{array}{c}\text { Tensile } \\
\text { modulus } \\
(\mathrm{GPa})\end{array}$ & $\begin{array}{c}\text { Flexural } \\
\text { strength } \\
(\mathrm{MPa})\end{array}$ & $\begin{array}{c}\text { Flexural } \\
\text { modulus } \\
(\mathrm{GPa})\end{array}$ & $\begin{array}{c}\text { Interlaminar } \\
\text { shear strength } \\
(\mathrm{MPa})\end{array}$ \\
\hline $\begin{array}{l}\text { Glass phenolic } \\
\text { (unmodified) comp. }\end{array}$ & 380 & $25 \cdot 7$ & 330 & 23.5 & 35 \\
$\begin{array}{l}\text { Glass phenolic } \\
\text { (modified) comp. }\end{array}$ & 475 & 42.6 & 470 & 42.5 & 49.5 \\
$\begin{array}{l}\text { Glass polyester } \\
\text { comp. }\end{array}$ & 340 & 40 & 267 & 30 & 26.5 \\
\begin{tabular}{l} 
Glass epoxy comp. \\
\hline
\end{tabular} & 465 & 45 & 310 & 40 & 40 \\
\hline
\end{tabular}


Table 2. Mechanical properties of PMC-II.

\begin{tabular}{lccccc}
\hline Material & $\begin{array}{c}\text { Tensile } \\
\text { strength } \\
(\mathrm{MPa})\end{array}$ & $\begin{array}{c}\text { Tensile } \\
\text { modulus } \\
(\mathrm{GPa})\end{array}$ & $\begin{array}{c}\text { Flexural } \\
\text { strength } \\
(\mathrm{MPa})\end{array}$ & $\begin{array}{c}\text { Flexural } \\
\text { modulus } \\
(\mathrm{GPa})\end{array}$ & $\begin{array}{c}\text { Interlaminar } \\
\text { shear strength } \\
(\mathrm{MPa})\end{array}$ \\
\hline $\begin{array}{l}\text { Epoxy reinforced } \\
\text { with 8H satin weave } \\
\text { glass fibres }\end{array}$ & 450.8 & 31.8 & 620.1 & 27.5 & 38.5 \\
$\begin{array}{l}\text { Epoxy reinforced } \\
\text { with 4H satin weave } \\
\text { glass fibres }\end{array}$ & 598.7 & 47.4 & 815.8 & 38.2 & 64.6 \\
$\begin{array}{l}\text { Epoxy reinforced } \\
\text { with plain weave } \\
\text { glass fibre }\end{array}$ & 370.4 & 27.4 & 390.8 & 23.2 & 37.1 \\
$\begin{array}{l}\text { Epoxy reinforced with } \\
\text { UD carbon fibre }\end{array}$ & 723 & 67.7 & 1101.6 & 96.3 & 38.7 \\
\hline
\end{tabular}

Table 3. Coefficient of restitution, dynamic hardness and strain rates during impact of PMC-I.

\begin{tabular}{lccc}
\hline Material & $\begin{array}{c}\text { Coefficient of } \\
\text { restitution }\end{array}$ & $\begin{array}{c}\text { Dynamic hardness } \\
(\mathrm{MPa})\end{array}$ & $\begin{array}{c}\text { Strain rate } \\
\left(\mathrm{sec}^{-1}\right)\end{array}$ \\
\hline $\begin{array}{l}\text { Glass phenolic } \\
\text { (unmodified) } \\
\text { comp. }\end{array}$ & 0.675 & 218.7 & 13.6 \\
$\begin{array}{l}\text { Glass phenolic } \\
\text { (modified) }\end{array}$ & 0.625 & 286.4 & 14.6 \\
$\begin{array}{l}\text { comp. } \\
\begin{array}{l}\text { Glass polyester } \\
\text { comp. }\end{array}\end{array}$ & 0.635 & 280.3 & 14.5 \\
$\begin{array}{l}\text { Glass epoxy } \\
\text { comp. }\end{array}$ & 0.68 & 341.3 & 15.2 \\
\hline
\end{tabular}

\subsection{Dynamic hardness}

As reported by Tirupataiah et al (1990), the coefficient of restitution (e) is related to the dynamic hardness, $H_{\mathrm{d}}$, of the target material as:

$$
e=\frac{1 \cdot 9 H_{d}^{5 / 8}}{E_{\mathrm{eff}}^{1 / 2} \rho_{\mathrm{b}}^{1 / 8} V^{1 / 4}}
$$

and

$$
H_{\mathrm{d}}=0 \cdot 36 e^{8 / 5} E_{\mathrm{eff}}^{4 / 5} \rho_{\mathrm{b}}^{1 / 5} V^{2 / 5} \text {, }
$$

where $\rho_{\mathrm{b}}$ is the density of the impacting ball, $V$ the velocity of impact, and $E_{\text {eff }}$ the effective modulus of the target-ball material combination, which on expansion can be written as:

$$
E_{\text {eff }}=\frac{E_{\mathrm{b}} E_{\mathrm{f}}}{\left(1-V_{\mathrm{b}}^{2}\right) E_{\mathrm{f}}+\left(1-V_{\mathrm{v}}^{2}\right) E_{\mathrm{b}}} .
$$

Table 4. Coefficient of restitution, dynamic hardness and strain rates during impact of PMC-II.

\begin{tabular}{lccc}
\hline Material & $\begin{array}{c}\text { Coefficient of } \\
\text { restitution }\end{array}$ & $\begin{array}{c}\text { Dynamic } \\
\text { hardness } \\
(\mathrm{MPa})\end{array}$ & $\begin{array}{c}\text { Strain rate } \\
\left(\mathrm{sec}^{-1}\right)\end{array}$ \\
\hline $\begin{array}{l}\text { Epoxy reinforced with } \\
\text { 8H satin weave glass } \\
\text { fibres }\end{array}$ & 0.64 & 239.1 & 13.7 \\
$\begin{array}{l}\text { Epoxy reinforced with } \\
\begin{array}{l}\text { 4H satin weave glass } \\
\text { fibres }\end{array}\end{array}$ & 0.64 & 321.9 & 15.0 \\
$\begin{array}{l}\text { Epoxy reinforced with } \\
\text { plain weave glass fibres }\end{array}$ & 0.66 & 224.5 & 13.7 \\
$\begin{array}{l}\text { Epoxy reinforced with } \\
\text { UD carbon fibres }\end{array}$ & 0.82 & 621.3 & 17.7 \\
\hline
\end{tabular}

Thus, using expressions (2) and (3), dynamic hardness values of various PMCs have been determined. These values are given in tables 3 and 4. For PMC-I, glassreinforced epoxy has the highest $H_{\mathrm{d}}$; and for PMC-II, unidirectional carbon fibre-reinforced epoxy has the highest $H_{\mathrm{d}}$. The $H_{\mathrm{d}}$ of this composite is two times or more compared to the $H_{\mathrm{d}}$ of other composites.

\section{Discussion}

\subsection{Strain rate}

The average strain $\left(\varepsilon_{\mathrm{av}}\right)$ pertinent to the deformation conditions discussed above is given by Tabor (1951) as:

$$
\varepsilon_{\mathrm{av}}=0 \cdot 1 \mathrm{~W} / r
$$

where $r$ is the ball radius, and $W$ the crater diameter which upon expansion (Sundararajan 1991), can be written as: 
Table 5. Correlation coefficient of the two parameters $e, H_{\mathrm{d}}$ with the mechanical properties of the PMCs.

\begin{tabular}{|c|c|c|c|c|}
\hline \multirow[b]{2}{*}{ Correlating parameters } & \multicolumn{2}{|c|}{ PMC-I } & \multicolumn{2}{|c|}{ PMC-II } \\
\hline & $e$ & $H_{\mathrm{d}}$ & $e$ & $H_{\mathrm{d}}$ \\
\hline $\begin{array}{l}e \text { vs tensile strength } \\
H_{\mathrm{d}} \text { vs tensile strength }\end{array}$ & 0.002 & $0 \cdot 318$ & 0.551 & $0 \cdot 852$ \\
\hline $\begin{array}{l}e \text { vs tensile modulus } \\
H_{\mathrm{d}} \text { vs tensile modulus }\end{array}$ & $0 \cdot 117$ & $0 \cdot 864$ & 0.711 & 0.935 \\
\hline $\begin{array}{l}e \text { vs flexural strength } \\
H_{\mathrm{d}} \text { vs flexural strength }\end{array}$ & 0.211 & 0.001 & 0.574 & 0.84 \\
\hline $\begin{array}{l}e \text { vs flexural modulus } \\
H_{\mathrm{d}} \text { vs flexural }\end{array}$ & $0 \cdot 102$ & 0.641 & 0.926 & 0.997 \\
\hline $\begin{array}{l}e \text { vs interlaminar shear strength } \\
H_{\mathrm{d}} \text { vs interlaminar shear strength }\end{array}$ & 0.025 & 0.068 & $0 \cdot 127$ & 0.006 \\
\hline
\end{tabular}

$$
W=2 \cdot 56 r \rho_{\mathrm{b}}^{1 / 4} V^{1 / 2} / H_{\mathrm{d}}^{1 / 4} .
$$

The time of impact between the ball and various composites is given by (Tabor 1951; Hutching 1977) as:

$$
t_{\mathrm{im}}=1 \cdot 28 r \rho_{\mathrm{b}} / H_{\mathrm{d}}^{1 / 2} \text {. }
$$

Thus average strain rate can be obtained as a $\varepsilon_{\mathrm{av}} / t_{\mathrm{im}}$ or $\dot{\varepsilon}_{\mathrm{av}}=0 \cdot 2 V^{1 / 2} H_{\mathrm{d}}^{1 / 4} / r \cdot \rho_{\mathrm{b}}^{3 / 4}$. The strain rates obtained for various composites are given in tables 3 and 4 . It is evident that the average strain rate is 12 to $17 \mathrm{sec}^{-1}$ for the PMCs. This is the strain rate at which most of the metallic material undergoes abrasive wear, and this strain rate is lower than the strain rate to which metals and alloys are subjected during erosive wear (Sundararajan 1995).

However, a few points to which attention needs to be drawn are: (i) As the time of contact between the ball and the PMC is very small, and although deformation behaviour of polymers is known to be time dependent, in the present investigation, therefore time dependence of deformation behaviour can be ignored. (ii) The contact time being very small, therefore the heat generated by the impact cannot dissipate away, thus resulting in a fully adiabatic deformation. (iii) The state of stress during impact being multi-axial compressive, as in the case of hardness, therefore permits all the materials to deform plastically. Thus, considering all these points, the equations used above, though derived for metals and alloys, are applicable for PMCs also.

\subsection{Correlation of $e, H_{\mathrm{d}}$ with the various mechanical properties}

The coefficient of restitution and the dynamic hardness of these composites are correlated with their mechanical properties. The correlation coefficient of the two parameters $e, H_{\mathrm{d}}$ with the mechanical properties, for PMC-I and PMC-II, are given in table 5. PMC-II shows better correlation of the two parameters with their mechanical properties than PMC-I. For all the composites, modulus correlate with $e$ or $H_{\mathrm{d}}$ to higher extent than strength. Furthermore, the correlation between modulus and $H_{\mathrm{d}}$ is higher than the correlation between modulus and $e$. While, best correlation is obtained with flexural modulus for both $e$ and $H_{\mathrm{d}}$ in PMC-II, tensile modulus exhibits better correlation with $e$ and $H_{\mathrm{d}}$ in PMC-I. Thus, an improvement in stiffness would lead to an increase in its $H_{\mathrm{d}}$ and $e$. Interestingly, very poor correlation is noticed between interlaminar shear strength and $e$ or $H_{\mathrm{d}}$ in all the PMCs. Interlaminar shear strength is dependent on the nature of fibre-matrix bond and does not affect $e$ or $H_{\mathrm{d}}$ directly. Thus correlation coefficients do not indicate any simple method of estimating dynamic properties from mechanical tests such as modulus and strength.

\section{Conclusions}

(I) Epoxy resin reinforced with unidirectional carbon fibre exhibits highest coefficient of restitution and dynamic hardness.

(II) Stiffness is an important property to predict $e$ and $H_{\mathrm{d}}$ of PMCs.

(III) Interlaminar sheer strength does not influence $e$ and $H_{\mathrm{d}}$ of PMC.

\section{Acknowledgements}

The author is grateful to DRDO for funding this work. $\mathrm{He}$ is also grateful to $\mathrm{Dr} \mathrm{G}$ Sundararajan, Director, International Advanced Research Centre for Powder Metallurgy and New Materials, Balapur, Hyderabad, for his constant encouragement.

\section{References}

Davis C D and Hunter S C 1960 J. Mech. Phys. Solids 8235

Hertz $\mathrm{H}$ and Reine 1891 J. Angew. Math. 92156

Hutching I M 1977 J. Phys. D. Appl. Phys. 10 L179

Mok C H and Duffy J 1965 Int. J. Mech. Sci. 7355

Singer A R and Evans R W 1980 Met. Technol. 71142

Sundararajan G 1991 Wear 145257

Sundararajan G 1995 Wear 186,187 129

Tabor D 1948 Proc. R. Soc. London Ser. A 192247

Tabor D 1951 The hardness of metals (Oxford: Clarendon Press)

Tirupataiah Y, Venkataraman B and Sundararajan G 1990 Mater. Sci. \& Engg. A124 133 